\title{
The elderly and AIDS: Coping strategies and health consequences in rural Tanzania
}

Julia Dayton

Population Council

Martha Ainsworth

Follow this and additional works at: https://knowledgecommons.popcouncil.org/departments_sbsr-pgy

Part of the Demography, Population, and Ecology Commons, Family, Life Course, and Society Commons, Gerontology Commons, and the International Public Health Commons How does access to this work benefit you? Let us know!

\section{Recommended Citation}

Dayton, Julia and Martha Ainsworth. 2002. "The elderly and AIDS: Coping strategies and health consequences in rural Tanzania," Policy Research Division Working Paper no. 160. New York: Population Council. 
The Elderly and AIDS:

$>$

$\mapsto$

Coping Strategies and

ค

Health Consequences

in Rural Tanzania

$\mathbb{I}$

u

Julia Dayton

$\simeq$

Martha Ainsworth

$\varangle$

[디

2002 No. 160

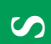

닥

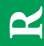

$>$

0

$\mapsto$

$\mapsto$

0

$5 \bigcirc \underset{19}{Y}$ E A R S S

$\epsilon$

1 Population Council 


\title{
The Elderly and AIDS: Coping Strategies and Health Consequences in Rural Tanzania
}

\author{
Julia Dayton \\ Martha Ainsworth
}

Julia Dayton is Research Associate, Policy Research Division, Population Council. At the time this paper was written, Martha Ainsworth was Senior Economist, Development Research Group, The World Bank, Washington, DC. Currently she is Coordinator, Health and Education Sector and Thematic Evaluation, Operations Evaluation Department, The World Bank. 


\begin{abstract}
The elderly are often especially likely to be adversely affected by the death from AIDS of prime-aged adults. The authors use a longitudinal survey of households from northwestern Tanzania in 1991-94 to compare the activities and wellbeing of the elderly in households before and after the death of a prime-aged adult with those of the elderly in households that did not experience the death of an adult. A significant proportion of adults suffering from AIDS return to their parents' home shortly before death. Time spent by the elderly performing household chores rises following an adult's death, and their participation in wage employment falls; no evidence is found of increased participation in farm work among the elderly. Evidence shows that the physical well-being of the elderly as measured by body mass index is reduced before the death of an adult relative but recovers thereafter. These results suggest that interventions to prevent a decline in well-being should be focused on the elderly in households with an AIDS patient during the period of illness. Finally, the physical well-being of the elderly in poor and better-off households prior to an adult's death is compared with that of the elderly in the poorest households that did not experience the death of an adult. The comparison indicates clearly that the poor have the lowest body mass index. Thus, deaths of adults from AIDS are likely to have the largest adverse impacts on the elderly in poor households. A broader group of elderly poor people with pervasive low health status should also be the focus of public policy designed to improve the welfare of the elderly.
\end{abstract}

This material may not be reproduced without written permission from the authors. For a list of Policy Research Division Working Papers, including those available for downloading in PDF format, see www.popcouncil.org/publications/wp/prd/rdwplist.html. 
The AIDS epidemic in sub-Saharan Africa is raising dramatically the mortality of prime-aged adults, leaving relatives who must cope emotionally and economically with the loss of a family member. The elderly are especially likely to be adversely affected by the death of prime-aged adults from AIDS (Barnett and Blaikie 1992; National Research Council 1996; Hunter and Williamson 1998; World Bank 2000).

The elderly could be affected by AIDS deaths in several ways. First, they may find themselves in households with no prime-aged adult and possibly left with the care of young and parentless children (Barnett and Blaikie 1992; Hunter and Williamson 1998). A recent analysis of Demographic and Health Survey data from sub-Saharan Africa found that orphaned children are more likely than others to live in grandparentheaded households (Bicego et al. forthcoming). Knodel and his colleagues (2000) reported that 74 percent of the orphans who lost both parents to AIDS in their sample of AIDS cases in Thailand were cared for by grandparents. Households lacking a primeaged adult are believed to be less viable economically and more demanding of the time and energy of the elderly who must care for children and generate income.

Second, the time use of the elderly in market and nonmarket activities may be affected. The elderly may spend time caring for family members with AIDS and may engage in activities to substitute for the labor the sickness has cost the household. In a study of six districts of Uganda, parents were most commonly cited as the principal caretaker for AIDS patients (Ntozi and Nakayama 1999). Knodel and his colleagues (2001a) found in Thailand that two-thirds of adults with AIDS coreside with or live near their parents and that a parent or older relative cared for 70 percent of adults who later died from AIDS. The vast majority of these parents were aged 50 or older, and most were older than 60. In contrast, according to a national study of the United States using data from 1990, only 13 percent of AIDS caregivers were older than 50, and only 6 percent were at least 60 (Turner et al. 1994). Following a death, work time may be diverted to performing mourning activities, and the elderly adult may have to increase participation in earning activities to replace the productivity of the deceased individual (Barnett and Blaikie 1992).

Ultimately, the illness and death of a prime-aged adult can affect the health status or physical well-being of the elderly through their impact on reducing household 
income, through the direct and indirect health effects of coping behaviors, and by raising the exposure of the elderly to disease vectors in the household. The burden of additional work (market work, housework, or caregiving) can contribute to a decline in an older person's health status. Given tight financial constraints caused by an adult's illness, the elderly may also receive less medical care or food so that more can be spent on the patient. In Thailand, Knodel et al. (2001b) found that elderly parents were the main source of funds for medical care for 60 percent of the AIDS patients who lived with their parents while ill, for 40 percent of the AIDS patients who lived adjacent to their parents, and for about 25 percent of the AIDS patients who lived at a distance from their parents. The loss of remittance income from adult children who die away from home may also result in lower incomes and poorer health status among the elderly.

Few studies have examined systematically the effects of the AIDS epidemic on the elderly in developing countries. Only the aforementioned study of Thailand collected quantitative evidence of the effect of adult AIDS morbidity and death on a relatively large sample of the elderly (Knodel et al. 2000, 2001a, 2001b). Using a purposive sample of 963 adults with symptomatic HIV and some who had died of AIDS, Knodel and his colleagues assessed the extent to which the elderly are the primary or secondary caregivers for AIDS patients and the propensity of patients to return to live with or near their elderly parents. ${ }^{1}$ Our study adds to this scanty literature by providing quantitative evidence from another cultural setting in a hard-hit region of Tanzania. In contrast to the Thai study, which assembled its sample of the elderly from index cases of AIDS patients, we use a longitudinal survey of a stratified random sample of households to compare the activities and welfare of the elderly in households before and after the death of a prime-aged adult with that of the elderly in households that did not experience an adult's death. This approach provides us with a control group of elderly individuals living in households in which no adult died during the survey period and with the ability to examine the impact on the elderly both before and after an adult's death. Although most of the deaths of adults in our survey were the result of AIDS, the sample is not sufficiently large to distinguish between the impact of AIDS deaths and that of deaths from other causes. Therefore, we examine the impact of adult mortality from any cause. 
We provide quantitative evidence of the impact of the deaths of prime-aged adults on the living arrangements, caregiving, medical consultations, market and nonmarket activities, and physical well-being of the elderly, as measured by their body mass index.

As in the Thai study, we find that a significant proportion of those who are dying return to their parents' home shortly before death. Following an adult's death, the proportion of the elderly living in households without a prime-aged adult (that is, in households with only other elderly people or children) rises to roughly the same proportion as for the elderly in households that did not experience an adult's death. As this study shows, time the elderly spend performing household chores rises following an adult's death, and their participation in wage employment decreases. We find no evidence of their increased participation in farm work. The physical well-being of the elderly is reduced before the death of an adult in the household, but it recovers afterward. These results suggest that interventions to prevent a decline in well-being should focus on the elderly in households with an AIDS patient during the period of illness. We compare the physical well-being of the elderly in households before an adult's death with that of older people in the poorest households that did not experience an adult's death. This comparison indicates that those living in the poorest households have the lowest body mass index. Thus, the deaths of adults in the prime of life are likely to have the largest adverse impacts on the elderly in poor households. An even broader group of the elderly poor with pervasive low health status should also be the focus of public policy designed to improve the welfare of older individuals.

\section{SETTING AND DATA}

The Kagera region lies in northwest Tanzania, adjacent to Lake Victoria and bordering Uganda, Rwanda, and Burundi. Of the 1.3 million people living in the region as of 1988 , more than 80 percent resided in rural areas, and most were engaged in agriculture: farming tree crops in the north and farming annual crops and tending livestock in the south. Annual household expenditure in 1991 was US\$217 per capita, ranging from US $\$ 118$ to US $\$ 357$ across Kagera's six districts. Kagera is characterized by high HIV prevalence and high adult mortality rates. A population-based seroprevalence survey con- 
ducted in 1987 found that about 25 percent of adults in the regional capital (Bukoba) and 10 percent of adults in rural areas surrounding Bukoba were infected with HIV (Killewo et al. 1990). Rates in other parts of Kagera were lower, with about 5 percent of adults infected in the west of Kagera and fewer than 1 percent of adults infected in the rural south and southwest. These levels of infection are similar to those currently estimated for Tanzania - a national infection rate of about 8 percent among prime-aged adults (UNAIDS 2000). A follow-up study in Kagera in 1993 found that HIV prevalence had declined among those aged 15-54 from 24 percent to 18 percent in urban Bukoba, and from 10 percent to 7 percent in the rural area surrounding Bukoba (Kwesigabo et al. 1998). In the latter case, however, the only population group that registered a significant decline was rural women aged $15-24 .^{2}$

\section{Source of data}

Data for this study are drawn from the Kagera Health and Development Survey (KHDS), a longitudinal living-standards survey of more than 800 households incorporating four waves of data collected at roughly six-month intervals from 1991 to 1994. The survey was designed to observe the impact of the deaths of prime-aged adults (defined here as those aged 15 to 50) on the welfare of surviving household members; therefore, the sample was heavily stratified to include a sufficient number of households likely to suffer the death of an adult during the short time frame of the panel (two and a half years). ${ }^{3}$ From each of the 51 primary sampling units, a sample of 16 households was chosen: 14 households were randomly selected from among those reporting either that an adult had died from illness or that an adult living in the household was too sick to work, or both; and two households were randomly selected from among those reporting neither situation. ${ }^{4} \mathrm{~A}$ total of 816 households were selected for the original sample, and 757 completed all four interviews. Detailed information was collected directly from each household member on his or her demographic characteristics, education, health status (acute and chronic), health expenditure, labor-force participation and time use, income, migration, remittances sent and received, savings, and height and weight. Information was also obtained on every household member and every nonresident relative who died before and during the survey. ${ }^{5}$ 


\section{Demographic characteristics of the elderly}

The present study focuses on persons older than 50 who resided in the 757 households that completed all four interviews in the panel. Because AIDS typically affects those aged 15-50, the sample is of the older generation. During the first interview (wave one), which occurred from October 1991 to March 1992, 566 household members older than 50 participated. The highest proportion of the elderly (41 percent) were in their fifties, 34 percent were in their sixties, and 26 percent were 70 or older (see Table 1).

Table 1 Percentage distribution of women and men older than 50, by selected demographic characteristics, wave one, Kagera, Tanzania, 1991-92

\begin{tabular}{|c|c|c|c|c|c|c|}
\hline \multirow[b]{2}{*}{ Characteristic } & \multicolumn{2}{|c|}{ Women } & \multicolumn{2}{|c|}{ Men } & \multicolumn{2}{|c|}{ Total } \\
\hline & Percent & (n) & Percent & (n) & Percent & (n) \\
\hline \multicolumn{7}{|l|}{$\overline{\text { Age }}$} \\
\hline $51-59$ & 42.1 & $(126)$ & 38.6 & $(103)$ & 40.5 & $(229)$ \\
\hline $60-69$ & 29.8 & (89) & 37.8 & $(101)$ & 33.6 & (190) \\
\hline $70-79$ & 16.7 & $(50)$ & 16.1 & (43) & 16.4 & (93) \\
\hline $80+$ & 11.4 & (34) & 7.5 & (20) & 9.5 & (54) \\
\hline Total & 100.0 & $(299)$ & 100.0 & $(267)$ & 100.0 & $(566)$ \\
\hline \multicolumn{7}{|l|}{ Years of completed schooling** } \\
\hline None & 75.6 & $(226)$ & 20.2 & (54) & 49.5 & $(280)$ \\
\hline $1-4$ & 21.4 & (64) & 47.9 & (128) & 33.9 & (192) \\
\hline $5-7$ & 3.0 & (9) & 27.7 & (74) & 14.7 & (83) \\
\hline $8+$ & 0.0 & (0) & 4.1 & (11) & 1.9 & (11) \\
\hline Total & 100.0 & $(299)$ & 100.0 & (267) & 100.0 & $(566)$ \\
\hline \multicolumn{7}{|l|}{ Marital status** } \\
\hline Married & 33.1 & (99) & 79.8 & (213) & 55.1 & $(312)$ \\
\hline Widowed & 53.2 & (159) & 14.2 & $(38)$ & 34.8 & (197) \\
\hline Divorced/separated & 13.7 & (41) & 4.5 & (12) & 9.4 & (53) \\
\hline Never married & 0.0 & $(0)$ & 1.5 & (4) & 0.7 & (4) \\
\hline Total & 100.0 & (299) & 100.0 & (267) & 100.0 & $(566)$ \\
\hline \multicolumn{7}{|l|}{ Relation to head** } \\
\hline Head & 33.8 & (101) & 96.6 & $(258)$ & 63.4 & $(359)$ \\
\hline Spouse of head & 32.1 & (96) & 0.7 & (2) & 17.3 & (98) \\
\hline Parent of head & 20.7 & (62) & 0.7 & (2) & 11.3 & (64) \\
\hline Other relative & 12.7 & (38) & 1.1 & (3) & 7.2 & (41) \\
\hline Not related & 0.7 & (2) & 0.7 & (2) & 0.7 & (4) \\
\hline Total & 100.0 & (299) & 100.0 & (267) & 100.0 & $(566)$ \\
\hline Coresiding with adult child** & 58.2 & (174) & 80.2 & (214) & 68.6 & $(388)$ \\
\hline No. living children $* *$ & 9.0 & $(27)$ & 2.6 & (7) & 6.0 & (34) \\
\hline Mean number of living children** & \multicolumn{2}{|c|}{4.5} & \multicolumn{2}{|c|}{8.9} & \multicolumn{2}{|c|}{6.6} \\
\hline
\end{tabular}

** The difference between men and women is statistically significant at $\mathrm{p} \leq 0.01$. 
Marked differences were found between women and men in terms of education, marital status, and relation to head of the household. Only about one-fourth of elderly women had any education, whereas 80 percent of elderly men had some schooling and more than a third had completed five years or more. Some 53 percent of the elderly women were widows, and only 33 percent were currently married, whereas 80 percent of elderly men were currently married and only 14 percent were widowers. These differences in elderly marital status by sex reflect lower male life expectancy and the tendency of men to marry younger women. Among married men and women in the sample, more than 90 percent were coresident with their spouses (not shown). Virtually all of the elderly men (97 percent) but only a third of the elderly women were household heads, and an additional third of women were married to the head. Around 21 percent of the elderly women were mothers of the head of household. Elderly women had half as many living children as did men (4.5 versus 8.9), and 9 percent of the women in the sample had no living children. ${ }^{6}$

Little movement of the elderly into and out of households was recorded (see Figure 1). Of the 566 people older than 50 seen in the first wave, 498 ( 88 percent) were still household members in wave four, two and a half years later. Thirty-eight elderly persons ( 7 percent) died during that period, and 45 ( 8 percent) moved out of the households. The numbers of elderly were boosted by arrivals and aging, however: 43 adult household members turned 51 and 40 moved in. Thus, the number of elderly at the end

Figure 1 Transitions of the elderly in Kagera region interviewed four times, Tanzania, 1991-94

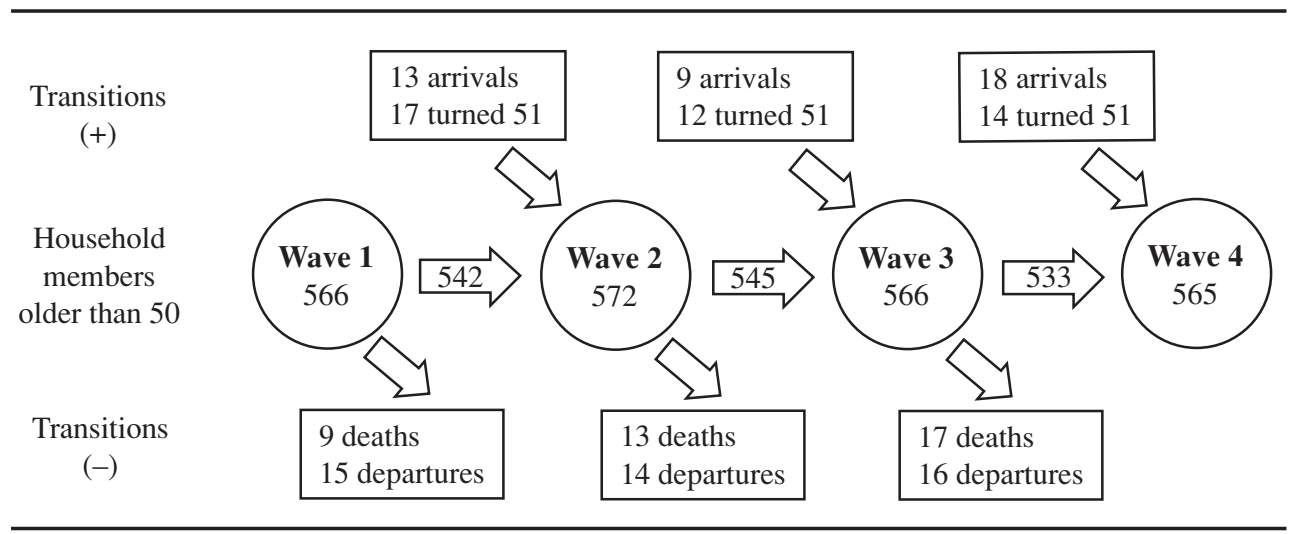


of the survey (565) in these households who were interviewed four times was similar to the number at the beginning. Household members older than 50 were the least likely of any age group to join or leave the Kagera households during the survey (Ainsworth and Semali 1995).

\section{DEATHS OF ADULTS IN THE HOUSEHOLDS OF THE ELDERLY}

Among the 757 households surveyed four times, 48 households with a coresident elderly person experienced an adult's death between the first and fourth wave. ${ }^{7}$ The 52 deaths in households that included elderly individuals were almost equally distributed between males and females, and 42 percent of the deceased were in the 25-to-34 age group (as shown in Table 2). ${ }^{8}$ Roughly a third of those who died (37 percent) had joined the household in the six to seven months between waves and were not recorded on the household roster before they died. The cause of death was reported by surviving household members, who were allowed to report both the diagnosis of a health practitioner and their own opinions about the cause. AIDS was reported as the cause of death by either the practitioner or the household in 22 cases ( 42 percent). If an additional 13 cases were included in which the diagnosis was ill-defined (for example, "other illness," "witchcraft") but for which the reported multiple symptoms were suggestive of AIDS (including weight loss, recurrent fever, chronic diarrhea, skin rash, genital sores) as well as two other cases diagnosed as tuberculosis, the proportion of deaths attributed to AIDS would have been as high as two-thirds ( 35 deaths, or 67 percent). The remaining causes of death

Table 2 Percentage distribution of deaths among people aged 15-50 in households with coresident elderly individuals, by age and sex of the deceased, Kagera, Tanzania, 1991-94

\begin{tabular}{|c|c|c|c|c|c|c|}
\hline \multirow[b]{2}{*}{ Age of deceased } & \multicolumn{2}{|c|}{ Women } & \multicolumn{2}{|c|}{ Men } & \multicolumn{2}{|c|}{ Total } \\
\hline & Percent & (n) & Percent & (n) & Percent & (n) \\
\hline $15-24$ & 18.5 & (5) & 8.0 & (2) & 13.5 & (7) \\
\hline $25-34$ & 25.9 & (7) & 60.0 & (15) & 42.3 & $(22)$ \\
\hline $35-44$ & 37.0 & (10) & 28.0 & (7) & 32.7 & (17) \\
\hline $45-50$ & 18.5 & (5) & 3.7 & (1) & 11.5 & $(6)$ \\
\hline Total & 100.0 & (27) & 100.0 & $(25)$ & 100.0 & $(52)$ \\
\hline
\end{tabular}


reported were accidents and childbirth ( 8 percent), malaria (6 percent), and other specific illnesses or ill-defined illnesses with symptoms not suggestive of AIDS (19 percent).

Among the 65 elderly people in households that experienced an adult's death, four lived in three households in which two adults died between waves one and four, while the remainder lived in households where one adult died. More than a third (35 percent) of the elderly in households experiencing an adult's death lost an adult son, 29 percent lost an adult daughter, equal numbers (5 percent) lost a brother, spouse, or niece, and 22 percent experienced the death of someone more distantly related or unrelated. ${ }^{9}$

Ten percent of the 642 elderly observed in all four waves lost a son or daughter in the 15-50 age group in the two and a half years included in the survey; roughly half were living with the adult child at the time of death, while the other half lost adult children living elsewhere (see Table 3). Moreover, 2 percent of the elderly lost a spouse.

\section{COPING BEHAVIOR OF THE ELDERLY AFTER A DEATH}

The elderly may be expected to reallocate their time or resources to care for household members with AIDS and to minimize the impact of the illness and death of an adult from AIDS.

\section{Living arrangements}

Some 73 percent of the elderly in wave one lived in households with all three generations, and 10 percent lived in households with prime-aged adults only. Another 10 percent of the elderly lived in households with children only, whereas 7 percent lived only with other elderly. Table 4 shows changes over time in the distribution of the eld-

Table 3 Percentage of elderly people in households surveyed who lost an adult child aged 15-50 or a spouse between waves one and four of study, Kagera, Tanzania, 1991-94

\begin{tabular}{lccc}
\hline Who died/where & $\begin{array}{c}\text { Elderly women } \\
(\mathbf{n = 3 4 9})\end{array}$ & $\begin{array}{c}\text { Elderly men } \\
(\mathbf{n}=\mathbf{2 9 3})\end{array}$ & $\begin{array}{c}\text { All elderly } \\
(\mathbf{n}=\mathbf{6 4 2})\end{array}$ \\
\hline Any adult child $^{\mathrm{a}}$ & 10.6 & 9.6 & 10.1 \\
Died in household & 5.7 & 5.1 & 5.5 \\
Died elsewhere & 5.2 & 4.8 & 5.0 \\
Spouse died in household & 2.9 & 1.4 & 2.2 \\
\hline
\end{tabular}

Note: None of the differences between men and women is statistically significant.

a Some of the elderly lost more than one adult child during the survey period. 
Table 4 Percentage distribution of the elderly households interviewed four times, by household composition and deaths of adults during the survey, Kagera, Tanzania, 1991-94

\begin{tabular}{|c|c|c|c|c|c|c|c|c|}
\hline \multirow{3}{*}{$\begin{array}{l}\text { Household } \\
\text { composition }\end{array}$} & \multicolumn{4}{|c|}{ Households with a death } & \multicolumn{4}{|c|}{ Households without a death } \\
\hline & \multicolumn{2}{|c|}{ Wave one } & \multicolumn{2}{|c|}{ Wave four } & \multicolumn{2}{|c|}{ Wave one } & \multicolumn{2}{|c|}{ Wave four } \\
\hline & Percent & (n) & Percent & (n) & Percent & (n) & Percent & (n) \\
\hline $\begin{array}{l}\text { Prime-aged adults, } \\
\text { elderly, children }\end{array}$ & 82.0 & $(41)$ & 67.3 & (37) & 72.1 & $(372)$ & 67.3 & (343) \\
\hline $\begin{array}{l}\text { Prime-aged adults, } \\
\text { elderly }\end{array}$ & 12.0 & (6) & 12.7 & (7) & 10.1 & $(52)$ & 9.4 & (48) \\
\hline Elderly, children & 6.0 & (3) & 12.7 & (7) & 10.5 & $(54)$ & 12.0 & (61) \\
\hline Elderly only & 0.0 & $(0)$ & 7.3 & (4) & 7.4 & $(38)$ & 11.4 & (58) \\
\hline Total & 100.0 & $(50)$ & 100.0 & $(55)$ & 100.0 & $(516)$ & 100.0 & $(510)$ \\
\hline $\begin{array}{l}\text { Percent living with no } \\
\text { prime-aged adult }\end{array}$ & 6.0 & - & 20.0 & - & 17.9 & - & 23.4 & - \\
\hline
\end{tabular}

erly by household composition in households that experienced an adult's death during the survey and in households that did not. The proportion of elderly living in households with no prime-aged adult increased in both types of households between waves one and four, regardless of whether an adult's death occurred (from 6 percent to 20 percent in households experiencing a death and from 18 percent to 23 percent in households that did not). Most of the change is explained by an increase in the number of elderly people living with other older individuals. Although before the death of an adult the proportion of elderly people living in households lacking a prime-aged adult is relatively small (6 percent), following an adult's death it reaches 20 percent, which is roughly the level found among the elderly in households where no such death occurred (23 percent). This finding is what might be expected if adult children stricken with AIDS are returning to live with their parents.

\section{Time use}

Table 5 indicates participation rates and mean hours spent by elderly men and women in health-related activities and in nonmarket and market activities in the seven days preceeding the first interview. Men and women were about equally likely to seek medical care for themselves (13-14 percent) or to care for sick household members (24 percent). Elderly women spent, on average, about twice as much time (2.2 hours) as did 
Table 5 Among the elderly coresident in households that experienced the death of a prime-aged adult, participation rates and mean hours spent in economic and coping activities in the seven days preceding the interview, by sex, wave one, Kagera, Tanzania, 1991

\begin{tabular}{|c|c|c|c|c|}
\hline \multirow[b]{2}{*}{ Activity } & \multicolumn{2}{|c|}{ Women $(n=299)$} & \multicolumn{2}{|c|}{$\operatorname{Men}(n=267)$} \\
\hline & $\begin{array}{l}\text { Participation } \\
\text { rate (percent) }\end{array}$ & $\begin{array}{l}\text { Mean } \\
\text { hours }\end{array}$ & $\begin{array}{l}\text { Participation } \\
\text { rate (percent) }\end{array}$ & $\begin{array}{l}\text { Mean } \\
\text { hours }\end{array}$ \\
\hline \multicolumn{5}{|l|}{ Health-related activity } \\
\hline Sought medical care & 13.0 & 0.55 & 14.2 & 0.56 \\
\hline Cared for the sick & 23.8 & $2.23 *$ & 24.0 & $1.18 *$ \\
\hline Mourned & $34.8 * *$ & $2.48 \sim$ & $45.7 * *$ & $3.57 \sim$ \\
\hline \multicolumn{5}{|l|}{ Nonmarket activity } \\
\hline Fetched water & $22.1 * *$ & $0.86^{* *}$ & $8.6 * *$ & $0.34 * *$ \\
\hline Collected firewood & $24.1 * *$ & $1.18 \sim$ & $34.5 * *$ & $1.51 \sim$ \\
\hline Performed housework & $72.9 * *$ & $10.71 * *$ & $28.8^{* *}$ & $2.18 * *$ \\
\hline \multicolumn{5}{|l|}{ Market activities } \\
\hline Performed wage work & $2.0 * *$ & $0.26 * *$ & $14.3 * *$ & $4.78 * *$ \\
\hline Farmed & 73.2 & 16.17 & 74.5 & 17.28 \\
\hline
\end{tabular}

* The female-male difference in participation rate or mean hours is statistically significant at $* \mathrm{p} \leq 0.05$;** $\mathrm{p} \leq$ $0.01 ; \sim \mathrm{p} \leq 0.10$.

elderly men (1.2 hours) caring for the sick, however. ${ }^{10}$ Elderly men were significantly more likely to have engaged in mourning activities (46 percent), compared with elderly women (35 percent), spending an average of 3.6 hours in the seven days following the death in mourning, compared with 2.5 hours among elderly women.

With respect to the other market and nonmarket activities reported in Table 5, for all activities except farming, statistically significant and sometimes large differences by sex are found in labor-force-participation rates and hours spent in such activities in the past seven days. Elderly women are far more likely than elderly men to fetch water and perform household chores. Elderly women spent, on average, 10.7 hours in the seven days before the survey on housework, compared with 2.2 hours for men. On the other hand, elderly men were much more likely to collect firewood and to engage in wage employment. In contrast, nearly three-fourths of elderly men and women were active in farming during the seven days before the survey, both of them performing roughly 16 to 17 of hours of farm work.

Table 6 shows selected results for changes in the participation rate of the elderly between the first and last waves of the survey in households that did and did not experi- 
Table 6 Among adults older than 50, participation rates and mean hours spent in coping and economic activities in the seven days preceding the survey interview during waves one and four in households that did and did not experience the death of a prime-aged adult, Kagera, Tanzania, 1991-94

\begin{tabular}{|c|c|c|c|c|}
\hline \multirow[b]{2}{*}{ Activity } & \multicolumn{2}{|c|}{ Households with a death } & \multicolumn{2}{|c|}{ Households without a death } \\
\hline & $\begin{array}{c}\text { Wave one } \\
\text { (before death) } \\
(\mathbf{n}=\mathbf{5 0})\end{array}$ & $\begin{array}{c}\text { Wave four } \\
\text { (after death) } \\
(\mathbf{n}=\mathbf{5 5})\end{array}$ & $\begin{array}{l}\text { Wave one } \\
(n=516)\end{array}$ & $\begin{array}{l}\text { Wave four } \\
(\mathbf{n}=\mathbf{5 0 7})\end{array}$ \\
\hline & \multicolumn{4}{|c|}{ Participation rates (percent) } \\
\hline Health-related activity & & & & \\
\hline Sought medical care & 16.0 & 9.1 & $13.4 * *$ & $7.5 * *$ \\
\hline Cared for the sick & 20.0 & $16.4^{\mathrm{c}}$ & $24.2 * *$ & $8.7^{\mathrm{c} * *}$ \\
\hline Mourned & 44.0 & 30.9 & 39.5 & 37.5 \\
\hline \multicolumn{5}{|l|}{ Nonmarket activity } \\
\hline Fetched water & 10.0 & $7.3^{\mathrm{c}}$ & 16.3 & $15.8^{c}$ \\
\hline Collected firewood & 22.0 & 20.0 & $29.7 *$ & $23.5^{*}$ \\
\hline Performed housework & 48.0 & 56.4 & 52.5 & 50.5 \\
\hline \multicolumn{5}{|l|}{ Market activity } \\
\hline Performed wage work & $16.0^{\mathrm{a}}$ & $11.1^{\mathrm{c}}$ & $7.0^{\mathrm{a}}$ & $5.3^{\mathrm{c}}$ \\
\hline Farmed & 66.0 & 65.5 & 74.6 & 74.9 \\
\hline & \multicolumn{4}{|c|}{ Mean hours } \\
\hline \multicolumn{5}{|l|}{ Health-related activity } \\
\hline Sought medical care & 0.97 & 0.67 & $0.52 *$ & $0.28 *$ \\
\hline Cared for the sick & 1.88 & $1.69^{\mathrm{c}}$ & $1.72 * *$ & $0.37^{\mathrm{c} * *}$ \\
\hline Mourned & 3.02 & 2.15 & 2.99 & 3.14 \\
\hline \multicolumn{5}{|l|}{ Nonmarket activity } \\
\hline Fetched water & $0.21^{\mathrm{b}}$ & $0.25^{\mathrm{b}}$ & $0.65^{\mathrm{b}}$ & $0.65^{\mathrm{b}}$ \\
\hline Collected firewood & $0.93^{c}$ & $0.57^{\mathrm{c}}$ & $1.37^{\circ * *}$ & $0.88^{\mathrm{c} * *}$ \\
\hline Performed housework & 6.12 & 7.35 & 6.74 & 7.03 \\
\hline \multicolumn{5}{|l|}{ Market activity } \\
\hline Performed wage work & $7.52^{\mathrm{a} *}$ & $4.65^{\mathrm{a} *}$ & $1.89^{\mathrm{a}}$ & $1.44^{\mathrm{a}}$ \\
\hline Farmed & $12.58^{\mathrm{a}}$ & $9.79^{\mathrm{a}}$ & $17.09^{\mathrm{a} * *}$ & $12.92^{\mathrm{a} * *}$ \\
\hline
\end{tabular}

Notes: The difference between the first and last wave is statistically significant at $* p \leq 0.05 ; * \mathrm{p} \leq 0.01 ; \sim \mathrm{p} \leq 0.10$. The difference between households with and without a death in the same wave is statistically significant at a $\mathrm{p} \leq$ $0.05 ; \mathrm{b} \mathrm{p} \leq 0.01 ; \mathrm{c} \mathrm{p} \leq 0.10$.

ence the death of a prime-aged adult during the survey. The proportion of the elderly caring for the sick declined significantly in households where no death occurred, whereas the proportion remained relatively high in households that experienced the death of an adult. This finding may reflect the fact that households experiencing an adult's death have generally higher levels of morbidity, whether from AIDS or other causes. The 
participation rate in housework remained constant in households in which no adult died, but rose from 48 percent to 56 percent in households experiencing a death. Although the increase in participation in housework is not statistically significant, in regressions for hours spent performing household activities (including household chores and caring for sick members), Beegle (1998) found that the death of a prime-aged adult in the past year was associated with an increase in hours spent on household activities for adults aged 51-65-just under four hours, on average. No statistically significant change was found in the participation rate in farming or wage employment among the elderly between households that experienced an adult's death and those that did not. On the other hand, the elderly in households in which an adult died were less likely in all waves to engage in farming and more than twice as likely to work in wage employment. ${ }^{11}$ This finding suggests important differences between households in which such a death eventually occurred and those that did not experience a death in wave one.

\section{IMPACT OF DEATHS OF ADULTS ON THE ELDERLY'S \\ PHYSICAL WELL-BEING}

Physical well-being is measured here using the body mass index (BMI), defined as the respondent's weight in kilograms divided by height in meters squared. BMI is considered a strong measure of overall health status for adults because it is predictive of morbidity and mortality in industrialized countries and responds to relatively short-term changes in energy inputs and outputs (Waaler 1984; Kushner 1993; WHO Expert Subcommittee 1998; Engelman et al. 1999; Duerksen et al. 2000; Stefanovic et al. 2000). Although both extreme low and high values of BMI are associated with higher risks of morbidity and mortality in industrialized countries, the highest risks in developing countries are associated with extremely low values, indicative of chronic energy deficiency (WHO Expert Committee 1995). We use 18.5 as the threshold for low BMI in this study, although we recognize that the precise definition of extreme values is subject to debate (Imminck et al. 1992; Garcia and Kennedy 1994; Strauss 1998).

The average (weighted) BMI of the elderly in Kagera was 20.3 in wave one (199192), about 20 percent lower than for the elderly population of the United States and lower than among samples of the elderly in three other developing countries for which 
information is available, namely Brazil, China, and Guatemala (Ainsworth and Dayton 2001). ${ }^{12}$ In Kagera and these three countries, the BMI of elderly women was generally greater than that for men, and BMI declined with age.

In Kagera, the elderly living in households that experienced the death of a primeaged person during the survey initially had a higher BMI (20.92) than those living in households that did not experience a death (20.27); this difference is not statistically significant (see Table 7). BMI improved over time in both groups, although the increase was greater for the elderly in households experiencing an adult's death. ${ }^{13}$ The difference in mean BMI between adults in the two groups in wave four is statistically significant. Multivariate regression analysis confirmed that the BMI of the elderly in households with a sick adult worsened during the illness and recovered after a death (Ainsworth and Dayton 2001).

This finding is demonstrated more clearly in the bottom row of Table 7, which shows the proportion of elderly people with a BMI lower that 18.5 living in households that did and did not experience an adult's death. Among those in households where an adult died during the survey, 28 percent had a low BMI before the death, declining to 18 percent after the death. Little change was found in low BMI among the elderly living in households that did not experience a death.

A strong positive relationship is also found between poverty and low BMI. Table 8 compares the wave one mean BMI and percent with low BMI among the elderly in three groups - the elderly in poor and in better-off households that did not experience an adult's death during the survey period and those in all households that eventually did

Table 7 Body mass index (BMI) among adults older than 50 during waves one and four of the study, in households that did and did not experience the death of a primeaged adult during the survey, Kagera, Tazania, 1991-94

\begin{tabular}{lcccccc}
\hline & \multicolumn{2}{c}{ Households with a death } & & \multicolumn{2}{c}{ Households without a death } \\
BMI & $\begin{array}{c}\text { Wave one } \\
\text { (before death) } \\
(\mathbf{n})=\mathbf{4 6}\end{array}$ & $\begin{array}{c}\text { Wave four } \\
(\text { after death }) \\
(\mathbf{n})=\mathbf{4 4}\end{array}$ & & $\begin{array}{c}\text { Wave one } \\
(\mathbf{n})=\mathbf{4 7 7}\end{array}$ & $\begin{array}{c}\text { Wave four } \\
(\mathbf{n})=\mathbf{4 6 1}\end{array}$ \\
\hline Mean BMI & 20.92 & $21.73^{*}$ & & 20.27 & $20.40^{*}$ \\
Percent with BMI $<18.5$ & 28.3 & 18.2 & & 30.2 & 28.9 \\
\hline
\end{tabular}

*The difference between household groups in wave four is statistically significant at $p \leq 0.05$.

Notes: The sample for this table includes only individuals observed in all four waves of the survey and for whom height and weight were available. The difference between household groups in percent with BMI $<18.5$ in wave four is not statistically significant $(\mathrm{p} \leq 0.132)$. 
Table 8 Body mass index (BMI) recorded in wave one among elderly in poor and better-off households that did not experience the death of a prime-aged adult during the survey, compared with BMI of the elderly in households that eventually experienced such a death, Kagera, Tanzania, 1991-94

\begin{tabular}{lcccc}
\hline & \multicolumn{2}{c}{ Elderly in households without a death } & $\begin{array}{c}\text { EIderly in } \\
\text { households } \\
\text { with a death }\end{array}$ \\
\cline { 2 - 5 } BMI & $\begin{array}{c}\text { Poot households } \\
(\mathbf{n}=\mathbf{1 9 1})\end{array}$ & $\begin{array}{c}\text { households } \\
(\mathbf{n}=\mathbf{2 8 6})\end{array}$ & $\begin{array}{c}\text { Total } \\
(\mathbf{n}=\mathbf{4 7 7})\end{array}$ & $\begin{array}{c}\text { Total } \\
(\mathbf{n}=\mathbf{4 6})\end{array}$ \\
\hline Mean BMI & $19.78^{* *}$ & $20.59 * *$ & 20.27 & 20.92 \\
Low BMI (percent) & $37.7 * *$ & $25.2^{* *}$ & 30.2 & 28.3 \\
\hline
\end{tabular}

Note: For definition of poor and better-off households, see endnote 14 .

** Differences between poor and better-off households are statistically significant at $\mathrm{p} \leq 0.01$.

experience one. ${ }^{14}$ The elderly living in poor households where no adult died had the lowest average BMI values (19.8) and were the most likely to have low BMI values (38 percent) of all three groups, including the elderly living in households that later experienced the death of an adult (mean of 20.92 and 28.3 percent with low BMI). This finding suggests that the elderly living in poor households are the most vulnerable of all the older people in our study, even more so than those experiencing a recent death and those who are about to experience one.

\section{Discussion AND Policy IMPLiCATIONS}

Policymakers in many developing countries are increasingly concerned that the elderly are particularly affected by the high mortality of prime-aged adults brought on by the AIDS epidemic. The impacts and mechanisms thought to be important include an increased proportion of households composed only of the elderly and their children and an increased burden of care for young children placed on the elderly; increased time spent by the elderly in caring for sick household members; a greater burden of housework and farm work among the elderly required to compensate for the lost labor of the person with AIDS; and reduced economic resources for the household. To the extent that coping mechanisms are unsuccessful in mitigating the impact of AIDS in the household or that they place an excessive burden on the elderly, the physical well-being of the elderly may decline. 
In this study, we examined the effects of the deaths of prime-aged adults on the elderly by using longitudinal household data from 1991-94 from the Kagera region of Tanzania. During this period, HIV infection rates were roughly 25 percent among adults in the main town of Bukoba, 10 percent in the surrounding rural areas, and in the rest of the region in the range of 1 to 5 percent. The adult mortality rate had already increased dramatically since the AIDS epidemic was first detected in the region in the early 1980s. Our data have some important advantages: a relatively large sample of the elderly; the ability to analyze their well-being both before and after the death of an adult household member in the prime of life; the ability to collect information directly from elderly respondents; the ability to control for household assets; and, perhaps most important, a control group of elderly people living in households that did not experience such a death. The number of elderly in households that experienced an adult's death surveyed during a period of two and a half years was relatively small (fewer than 60 , or about 10 percent of the elderly in the sample). Nevertheless, in the midst of a devastating AIDS epidemic that has doubled, tripled, or perhaps quadrupled the mortality of prime-aged adults, a minority of the elderly had to care for terminally ill adult children in a given year. This finding suggests the feasibility of devising an effective public response.

Although the results from the Kagera region of Tanzania are from a different continent, several findings are similar to those of the analyses of the situation in Thailand by Khodel and his colleagues. First, in both countries a strong tendency was found for terminally ill adults to return to their home areas or to their parents' homes before they died. In Kagera about 37 percent of those who died entered the household in the six or seven months between survey waves. In the Thai sample, virtually the same percentage of those who died returned to their "place of origin" during their illness (Knodel et al. 2001a). Second, a strong tendency was seen for terminally ill adults to coreside with or live near their parents. In Kagera, nearly two-thirds of the elderly living in households where an adult died lost a coresident son or daughter. In the Thai sample, a parent or other elderly relative provided care to 70 percent of adult AIDS patients living in the household or nearby (Knodel et al. 2001a).

The Kagera data also inform the nature and timing of the impact of the deaths of prime-aged adults on the elderly. The elderly were demographically a stable group, with 
few departures from or arrivals into households during the two-and-a-half-year study. Among the elderly who lost adult children, half lost children who were coresident and half lost children who died away from their parents' home. Following an adult's death, the elderly were more likely to find themselves in a household that lacked a prime-aged adult (that is, in a household with only other elderly people or children), but this rate was similar to the rate found among the elderly living in households that experienced no such death. ${ }^{15}$ Elderly women and men were equally likely to care for sick household members, but women spent two times the number of hours as did men in caring for the sick. The elderly in households suffering the death of a prime-aged adult engaged in more housework following the death but, contrary to expectations, did not increase market-related activities such as farming and wage work to compensate for lost income. Several explanations for this finding include the possibility that the elderly have a comparative advantage among members of the household in doing housework compared with performing market-related activities, that other household members increase their economic activities to compensate, that income losses are balanced by increased remittances or inheritances, or that the primary economic shock to household income occurs before the death, during the prolonged illness associated with AIDS. Perhaps the most informative result for policy planning is the finding that the elderly living in households where an adult has died have a lower body mass index before the death occurs and that the BMI tends to improve after the death.

The results for Kagera also confirm the benefits of panel data for analyzing the impact of AIDS deaths on the elderly. Households of differing economic status are not equally likely to experience deaths related to AIDS. In sub-Saharan Africa throughout the 1990s, adults with comparatively greater wealth and more schooling who worked at more jobs requiring skills were more likely to be infected with HIV (Ainsworth and Semali 1998; World Bank 1999). This positive correlation between HIV infection and economic status is, in fact, a reversal of the normal relationship between income on one hand and health and life expectancy on the other (World Bank 1993). As a result, on average, initial health conditions in households that eventually suffer an AIDS-related death may be better than those in households not experiencing such deaths, confounding ex-post analysis of the impact of those deaths on the elderly. To disentangle these ef- 
fects, it is useful to have multiple observations of the elderly over time, before and after an adult's death. Without panel data, we would not have been able to confirm a loss in physical well-being over time and its eventual recovery among the households that experience the death of a prime-aged adult.

Two main policy implications emerge from the findings. First, the period before the death of an adult, when a terminally ill person is living with the family, appears to be the most stressful for the elderly in terms of reductions in their physical well-being. This period is one in which interventions might have the greatest impact by mitigating adverse effects. ${ }^{16}$ Second, in focusing efforts on reducing the impact of AIDS mortality on the elderly, policymakers should not lose sight of the high correlation between poverty and low health status of the elderly even in households that have not experienced the death of an adult. Thus, although specific short-term efforts may be needed to alleviate the impact of adult AIDS-related deaths on the elderly, particularly the elderly in poor households, policymakers should also seek to improve the longer-term health status of the much larger population of elderly poor and to slow the spread of HIV/AIDS.

\section{NOTES}

1 The unit of analysis was generally the person with AIDS, but in some cases it was the parent of the AIDS patient. The sample was constructed using key informants, including health personnel and community leaders, at 85 sites in eight of Thailand's 76 provinces and in Bangkok, representing all regions and both urban and rural areas. Although it was not a probability sample, the demographic characteristics of the AIDS patients in the sample were similar to those of reported AIDS cases in Thailand. The caregivers and patients were not directly interviewed in the Thai study, however. All information about the patient and caregivers was supplied by health providers and other key informants.

2 The decline in prevalence in part reflects high mortality. Because HIV infection is lifelong, the only way prevalence can decline over time in a cohort is for the mortality rate to exceed the new infection rate (incidence) or for HIV-positive people to leave the study population by aging or migrating from the region. 
3 Fifty-one primary sampling units were chosen from high- and low-mortality communities in each of four geographic zones of the region. An exhaustive listing was made of all households in these sampling units, more than 29,000 households in total; respondents in each of the households were asked about the recent (in the previous 12 months) mortality of prime-aged adults, the cause of death (illness, accident, childbirth, other), and whether any adults in the household were too sick to work.

4 The majority of adults reporting illness (in the first group of households) recovered fully.

5 The questionnaire and sampling are described in greater detail in Ainsworth et al. (1992).

6 Almost half of these 27 women had never borne children.

7 Eighty-two of the 757 households experienced an adult's death between the first and fourth waves. Here, we highlight those deaths that occurred in households with elderly members present in at least one of the four waves.

8 The age distribution of these deaths by sex does not display the often observed higher death rates at younger ages of women among people with HIV/AIDS. The table describes, however, only deaths in households including elderly people, and fatally ill adults with specific characteristics may choose to join such households. Furthermore, probably about one-third of the deaths recorded are not AIDSrelated. Analysis of all deaths in households at any time during the survey reveals the familiar pattern suggesting lower age at mortality for women than men because of earlier HIV infection (see Ainsworth and Semali 1998).

9 In addition, one elderly person lost a sister, one a daughter-in-law, and one a grandchild. The percentages add to more than 100 because some of the elderly were in households that experienced two deaths.

10 Beegle (1998) found in this same data set that men and women aged 50-65 were the second most likely to be caring for sick household members, after women aged $15-50$. 
11 Beegle (1998) found no evidence that the elderly work more hours per week on the farm as a consequence of the death of an adult in the past year.

12 We were unable to find any references for BMI of the elderly for other subSaharan countries.

13 This change does not account for mortality in our sample. Of the 697 people older than 50 ever observed, 34 died during the survey, five of them in households experiencing the death of a prime-aged adult. Although the occurrence of such a death during the survey bore no relation to the probability of death for the elderly adult, higher BMI reduced the risk of death.

14 The elderly were classified as living in poor or better-off households as follows: The 757 households surveyed in all four waves were divided into two equal groups - households with less than the median value of household assets per capita in wave one ("poor"), and households with higher than the median value of assets per capita in wave one ("better-off"). In Table 8, 191 elderly people in households that did not experience a death fell into the poor category and 286 in the better-off category. This finding is consistent with the observation across all 757 households that better-off households were much more likely to include an elderly person (66 percent) than were poor households (47 percent).

15 Of course, the proportion of the elderly living only with children can also be driven upward by AIDS mortality even if the death does not occur in the household of the elderly adult as a result of the entrance of orphaned and fostered children.

16 Using the same data set, Ainsworth and Semali (2002) reach similar conclusions about the trends in wasting and stunting of children younger than age five .

\section{ACKNOWLEDGMENTS}

This paper is based on the research project entitled "The economic impact of fatal adult illness due to AIDS and other causes in sub-Saharan Africa," sponsored by the World Bank, USAID, and Danida. The project was conducted as a collaboration between the World Bank (Mead Over, principal investigator; Martha Ainsworth, 
coinvestigator) and the University of Dar es Salaam (Phare Mujinja, Innocent Semali, and Godlike Koda, coinvestigators). The authors are grateful to UNAIDS, particularly to Anita Alban, for financial support; to Paurvi Bhatt, Deon Filmer, Robert Hecht, John Knodel, Sukhontha Kongsin, and John Stover for comments on an earlier draft; and to Anna Marie Marañon and Hilary Brougher for expert production assistance.

\section{REFERENCES}

Ainsworth, M., G. Koda, G. Lwihula, P. Mujinja, M. Over, and I. Semali. 1992. "Measuring the Impact of Fatal Adult Illness in sub-Saharan Africa: An Annotated Household Questionnaire.” LSMS Working Paper No. 90. Washington, DC: World Bank.

Ainsworth, M. and I. Semali. 1995. "The impact of adult deaths on household composition.” World Bank and Muhimbili University College of Health Sciences. Unpublished.

- 1998. "Who is most likely to die of AIDS? Socioeconomic correlates of adult deaths in Kagera Region, Tanzania." In M. Ainsworth, L. Fransen, and M. Over (eds.), Confronting AIDS: Evidence from the Developing World. Brussels: European Commission.

- 2002. "The impact of adult deaths on children's height and weight: Evidence from Tanzania." Unpublished.

Ainsworth, M. and J. Dayton. 2001. "The impact of the AIDS epidemic on the health of the elderly in northwestern Tanzania." Unpublished.

Barnett, T. and P. Blaikie. 1992. AIDS in Africa: Its Present and Future Impact. London: Belhaven Press.

Beegle, K. 1998. "The impact of adult mortality on households: Evidence from rural Tanzania.” Santa Monica, CA: RAND Corporation. Unpublished.

Bicego, G., S. Rutstein, and K. Johnson. Forthcoming. "Dimensions of the emerging orphan crisis in sub-Saharan Africa." Social Science \& Medicine. 
Duerksen, D.R., T.A. Yeo, J.L. Siemens, and M.P. O'Connor. 2000. "The validity and reproducibility of clinical assessment of nutritional status in the elderly." Nutrition 16(9): 740-744.

Engelman, D.T., D.H. Adams, J.G. Byrne, S.F. Aranki, J.J. Collins Jr., G.S. Couper, E.N. Allred, L.H. Cohn, and R.J. Rizzo. 1999. "Impact of body mass index and albumin on morbidity and mortality after cardiac surgery." Journal of Thoracic and Cardiovascular Surgery 118(5): 866-873.

Garcia, M. and E. Kennedy. 1994. "Assessing the linkages between low body mass index and morbidity in adults: Evidence from four developing countries." European Journal of Clinical Nutrition 48 (Supplement 3): S90-S96.

Hunter, S. and J. Williamson. 1998. Children on the Brink: Strategies to Support a Generation Isolated by HIVIAIDS. Washington, DC: United States Agency for International Development.

Immink, M.D., R. Flores, and E.O. Diaz. 1992. "Body mass index, body composition, and the chronic energy deficiency classification of rural adult populations in Guatemala." European Journal of Clinical Nutrition 46(6): 419-427.

Killewo J., K. Nyamuryekunge, A. Sandstrom, U. Bredberg-Raden, S. Wall, F. Mhalu, and G. Biberfeld. 1990. "Prevalence of HIV-1 infection in the Kagera region of Tanzania: A population-based study." AIDS 4(11): 1081-1085.

Knodel, J., C. Saengthienchai, W. Im-em, and M. VanLandingham. 2000. "The Impact of Thailand's AIDS Epidemic on Older Persons: Quantitative Evidence from a Survey of Key Informants." Population Studies Center Report No. 00-448. Ann Arbor: University of Michigan.

Knodel, J., M. VanLandingham, C. Saengtienchai, and W. Im-em. 2001a. "Older people and AIDS: Quantitative evidence of the impact in Thailand." Social Science \& Medicine 52: 1313-1327.

Knodel, J., C. Saengthienchai, W. Im-em, and M. VanLandingham. 2001b. "The impact of AIDS on parents and families in Thailand: A key informant approach." Research on Aging 23(6): 633-670. 
Kushner, R.F. 1993. "Body weight and mortality.” Nutrition Review 51(5): 127-136.

Kwesigabo, G., J. Killewo, C. Godoy, W. Urassa, E. Mbena, F. Mhalu, G. Biberfield, S. Wall, and A. Sandstrom. 1998. "Decline in the prevalence of HIV-1 infection in young women in the Kagera region of Tanzania." Journal of Acquired Immune Deficiency Syndrome and Human Retrovirology 17(3): 262-268.

National Research Council. 1996. Preventing and Mitigating AIDS in sub-Saharan Africa: Research and Data Priorities for the Social and Behavioral Sciences. Washington, DC: National Academy Press.

Ntozi, J.P.M. and S. Nakayama. 1999. "AIDS in Uganda: How has the household coped with the epidemic?" In The Continuing HIVIAIDS Epidemic in Africa: Responses and Coping Strategies. I.O. Orubuloye, J.C. Caldwell, and J.P.N. Ntozi, eds. Canberra: Health Transition Centre, National Centre for Epidemiology and Population Health, Australian National University.

Stefanovic, V., M. Stajonovic, and V. Djordjevic. 2000. "Effects of adequacy of dialysis and nutrition on morbidity and working in rehabilitation of patients treated by maintenance hemodialysis." International Journal of Artificial Organs 23(2): 83-89.

Strauss, J. and D. Thomas. 1998. "Health, nutrition and economic development." Journal of Economic Literature 36(2): 766-817.

Turner, H.A., J.A. Catania, and J. Gagnon. 1994. "The prevalence of informal caregiving to persons with AIDS in the United States: Caregiving characteristics and their implications." Social Science \& Medicine 38(11): 1543-1552.

UNAIDS. 2000. United Republic of Tanzania Epidemiological Fact Sheets on AIDS and Sexually Transmitted Infections. Geneva: UNAIDS and World Health Organization.

Waaler, H. 1984. "Height, weight and mortality: The Norwegian experience." Acta Medica Scandinavia (Supplement 679).

World Bank. 1993. World Development Report 1993: Investing in Health. New York: Oxford University Press. - 1999. Confronting AIDS: Public Priorities in a Global Epidemic. Revised edition. New York: Oxford University Press. 
- 2000. Intensifying Action Against HIV/AIDS in Africa. Africa Region. Washington, DC: World Bank.

World Health Organization (WHO) Expert Committee. 1995. "Physical Status: The Use and Interpretation of Anthropometry." WHO Technical Report Series No. 854. Geneva: WHO.

1998. "Uses and interpretation of anthropometry in the assessment of physical status: Report to the Nutrition Unit of the World Health Organization." Journal of Nutrition, Health \& Aging 2: 5-17. 


\title{
POLICY RESEARCH DIVISION WORKING PAPERS
}

\author{
Recent Back Issues
}

133 Mary Arends-Kuenning and Sajeda Amin, "The effects of schooling incentive programs on household resource allocation in Bangladesh."

134 John Bongaarts and Charles F. Westoff, "The potential role of contraception in reducing abortion."

135 John B. Casterline and Steven W. Sinding, "Unmet need for family planning in developing countries and implications for population policy."

*136 Carol E. Kaufman, Thea de Wet, and Jonathan Stadler, "Adolescent pregnancy and parenthood in South Africa."

*137 Valerie L. Durrant and Zeba A. Sathar, "Greater investments in children through women's empowerment: A key to demographic change in Pakistan?"

138 Sajeda Amin, Alaka Malwade Basu, and Rob Stephenson, "Spatial variation in contraceptive use in Bangladesh: Looking beyond the borders."
139 Geoffrey McNicoll, "Managing population-environment systems: Problems of institutional design."

140 Barbara S. Mensch, Barbara L. Ibrahim, Susan M. Lee, and Omaima ElGibaly, "Socialization to gender roles and marriage among Egyptian adolescents."

141 John Bongaarts and Elof Johansson, "Future trends in contraception in the developing world: Prevalence and method mix."

142 Alaka Malwade Basu and Sajeda Amin, "Some preconditions for fertility decline in Bengal: History, language identity, and an openness to innovations."

143 Zeba Sathar, Cynthia B. Lloyd, Cem Mete, and Minhaj ul Haque, "Schooling opportunities for girls as a stimulus for fertility change in rural $\mathrm{Pa}-$ kistan."

* No longer available 
144 John Bongaarts, "Household size and composition in the developing world."

145 John B. Casterline, Zeba A. Sathar, and Minhaj ul Haque, "Obstacles to contraceptive use in Pakistan: A study in Punjab."

146 Zachary Zimmer, Albert I. Hermalin, and Hui-Sheng Lin, "Whose education counts? The impact of grown children's education on the physical functioning of their parents in Taiwan."

147 Philomena Nyarko, Brian Pence, and Cornelius Debpuur, "Immunization status and child survival in rural Ghana."

148 John Bongaarts and Zachary Zimmer, "Living arrangements of older adults in the developing world: An analysis of DHS household surveys."

149 Markos Ezra, "Ecological degradation, rural poverty, and migration in Ethiopia: A contextual analysis."
150 Cynthia B. Lloyd, Sahar El Tawila, Wesley H. Clark, and Barbara S. Mensch, "Determinants of educational attainment among adolescents in Egypt: Does school quality make a difference?"

151 Barbara S. Mensch, Paul C. Hewett, and Annabel Erulkar, " The reporting of sensitive behavior among adolescents: A methodological experiment in Kenya."

152 John Bongaarts, "The end of the fertility transition in the developed world."

153 Mark R. Montgomery, GebreEgziabher Kiros, Dominic Agyeman, John B. Casterline, Peter Aglobitse, and Paul Hewett, "Social networks and contraceptive dynamics in southern Ghana."

154 Paul C. Hewett and Mark R. Montgomery, "Poverty and public services in developing-country cities." 
155 Zachary Zimmer, Linda G. Martin, and Ming-Cheng Chang, "Changes in functional limitations and survival among the elderly in Taiwan: 1993, 1996, and 1999."

156 John Bongaarts and Griffith Feeney, "How long do we live?"

157 Zachary Zimmer and Sovan Kiry Kim, "Living arrangements and socio-demographic conditions of older adults in Cambodia."
158 Geoffrey McNicoll, "Demographic factors in East Asian regional integration."

159 Carol E. Kaufman, Shelley Clark, Ntsiki Manzini, and Julian May, "How community structures of time and opportunity shape adolescent sexual behavior in South Africa."

160 Julia Dayton and Martha Ainsworth, "The elderly and AIDS: Coping strategies and health consequences in rural Tanzania." 